\title{
Self-assembling hydrogels based on a complementary host-guest peptide amphiphile pair
}

\author{
Carlos Redondo-Gómez, ${ }^{,, \neq}$Yamin Abdouni, ${ }^{,+\neq}$C. Remzi Becer, ${ }^{,, \S}$ and Alvaro Mata ${ }^{\star},+, \neq$
}

$\uparrow$ School of Engineering and Materials Science and $\$$ Institute of Bioengineering, Queen Mary University of London, London E1 4NS, United Kingdom

$\S$ Department of Chemistry, University of Warwick, Coventry CV4 7AL, United Kingdom

Tel: +44 7784134988, e-mail: a.mata@qmul.ac.uk

* Correspondence to Dr. Alvaro Mata

\section{Supporting Information}

\section{Table of Contents}

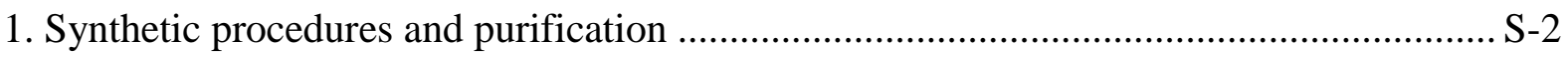

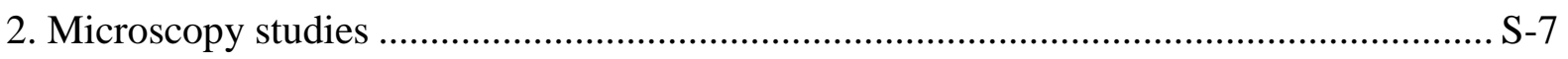

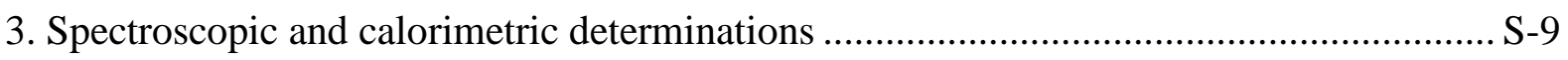

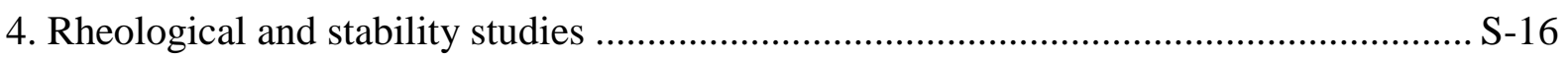

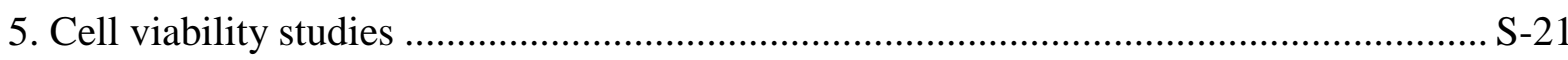




\section{Synthetic procedures and purification}

\section{General considerations}

PAs were synthesised using 4-methylbenzhydrylamine (MBHA) Rink Amide resin (0.52 $\mathrm{mmol} / \mathrm{g}$, Novabiochem Corporation, UK). In the case of $\boldsymbol{\beta C D}-\mathbf{P A}$ and Ada-PA the resin was bromoacetylated and functionalised with propargylamine following the peptoid synthesis solid phase submonomer method. ${ }^{1}$

\section{Bromoacetylation and propargylation of the MBHA resin}

The bromoacetylation was carried out as follows (Scheme S1): In a dry and Argon flushed reactor 10 equivalents of bromoacetic acid $\mathbf{1}$ and 5 equivalents of N,N'diisopropylcarbodiimide (DIC) were dissolved in $5 \mathrm{~mL}$ of dry DCM, the mixture was stirred for $30 \mathrm{~min}$ and then transferred to another vessel containing previously DCM swollen and Fmoc deprotected resin. The mixture was shaken for $2 \mathrm{~h}$, filtered off, washed with DCM and DMF four times. The resin-bound bromide 5 was then displaced with propargylamine (10 equivalents in $5 \mathrm{~mL}$ of DMF), shaken for $8 \mathrm{~h}$ at room temperature, filtered and washed three times with DMF, methanol, chloroform and diethyl ether respectively. In this fashion, propargylated MHBA resin 6 was afforded.

\section{Synthesis of $\boldsymbol{\beta C D}-\mathbf{P A}$}

For the synthesis of $\boldsymbol{\beta C D}$-PA, propargylated resin $\mathbf{6}$ was loaded in an automated peptide synthesiser (CS Bio, USA), solid phase peptide synthesis (SPPS) couplings were performed using four equivalents of Fmoc-protected amino acids (Novabiochem Corporation, UK), four equivalents of 1-hydroxybenzotriazole (HOBT, Carbosynth Limited, UK) and six equivalents of N,N'-diisopropylcarbodiimide (DIC, Sigma-Aldrich, UK), Fmoc deprotections were performed with $20 \%$ piperidine (Sigma-Aldrich, UK) in DMF. Following Fmoc removal from the $\mathrm{N}$-terminus the palmitoyl tail was manually conjugated using four equivalents of palmitic acid (Calbiochem, UK), four equivalents of HOBT, six equivalents of DIC in DMF/DCM 2:3 until negative for Kaiser Test, tail-coupled peptide $\mathbf{8}$ was afforded in this fashion. 6Monodeoxy-6-monoazido-beta-cyclodextrin $\left(\mathrm{N}_{3}-\beta \mathrm{CD}\right)$ was prepared as reported ${ }^{2,3}$ and clicked to the PA backbone through a copper(I)-catalized azide-alkyne cycloaddition (CuAAC) procedure as reported in literature. ${ }^{4}$ Cleaving of the crude $\boldsymbol{\beta C D}$-PA product from the resin was carried out using a mixture of TFA (Sigma-Aldrich, UK)/triisopropylsilane (TIS, Alfa Aesar, $\mathrm{UK}) /$ water $(95: 2.5: 2.5)$ for $3 \mathrm{~h}$ at room temperature, solvent was removed in vacuo allowing the precipitation of the peptide $9(\boldsymbol{\beta C D}-\mathbf{P A})$ using diethylether at $-20^{\circ} \mathrm{C}$. 

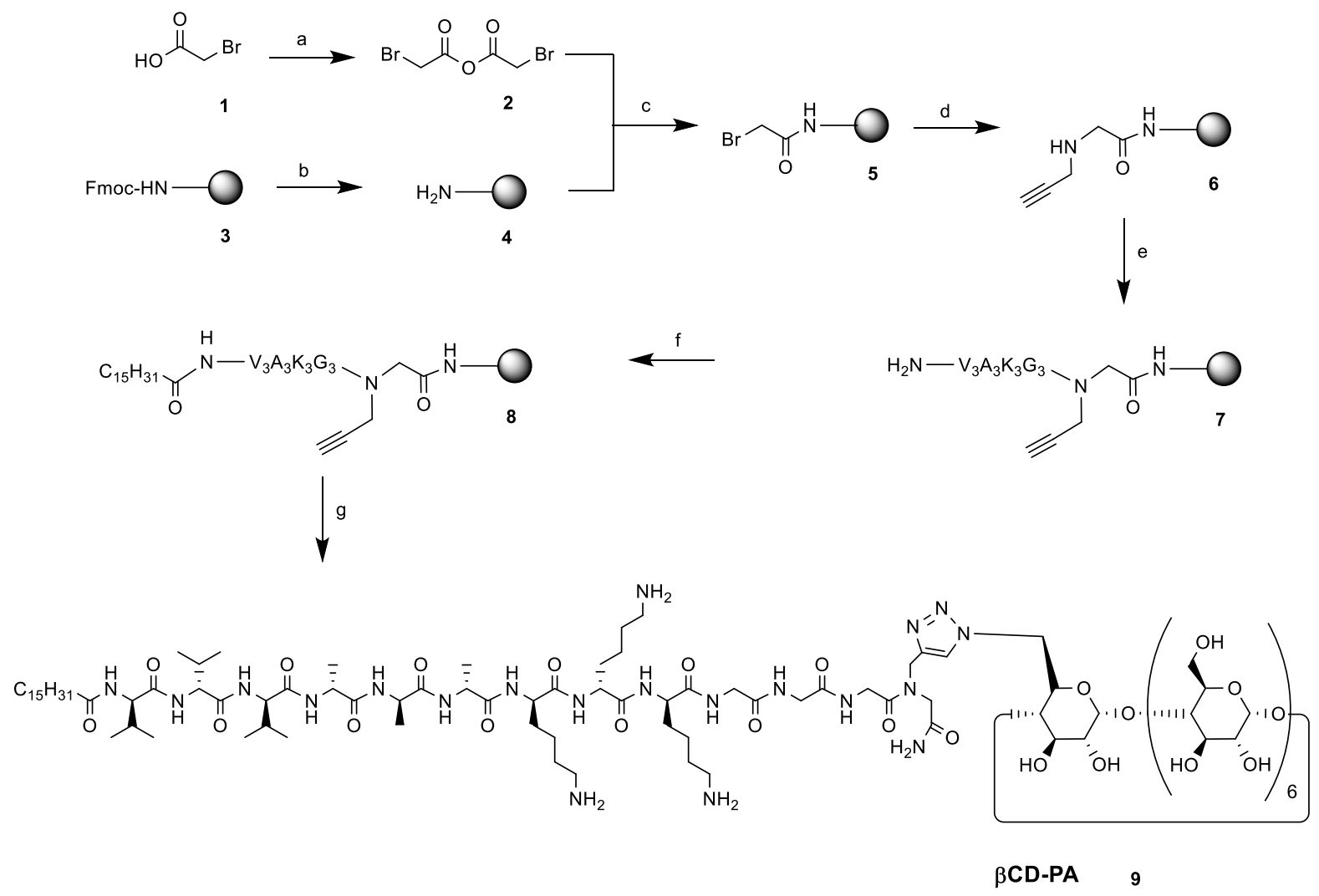

Scheme S1. Synthetic route followed for the preparation of $\boldsymbol{\beta C D - P A}$. a) Bromoacetic acid 10 eq., DIC 5 eq., DCM, r.t., 30 min. b) MHBA resin, piperidine $20 \%$ in DMF, r.t., 15 min. c) DCM, r.t., 2 h. d) Propargylamine 20 eq., DMF, r.t., 8 h. e) SPPS. f) Palmitic acid/HOBT/DIC 4:4:6 in DMF/DCM 2:3, r.t., 3 h. g) 1 . CuBr/ascorbic acid/ $\mathrm{N}_{3}-\beta C D$ in DMF/acetonitrile, DIPEA, 2,6-lutidine, r.t., 8 h; 2. TFA/TIPS/Water, r.t., 3 h. 


\section{Synthesis of Ada-PA}

The synthesis of Ada-PA (Scheme S2) firstly involved the clicking of the propargylated resin 6 with 1-azidoadamantane to afford the triazole 10, further Fmoc SPPS, alkyl tail coupling and cleaving operations were performed as described above to afford the adamantane peptide $\mathbf{1 2}$. Copper traces were removed using an alumina flash column in both host-guest PAs before undergoing further purification. Purification of all peptides was carried out through reversephase High-Performance Liquid Chromatography (HPLC) using a 2545 Binary Gradient Preparative HPLC (Waters, USA), a C18 column (Atlantis Prep OBD T3 Column, Waters, USA) and a gradient of 2-100\% acetonitrile in water (0.1 v/v\% TFA) over $40 \mathrm{~min}$. Detection was carried out concomitantly with $2489 \mathrm{UV} / \mathrm{Visible}$ and an electrospray ionisation mass spectrometer detector (ESI-MS) (Waters, USA). Peptide purity was determined by analytical HPLC as well as ESI-MS (Thermo LXQ, Thermo Scientific, USA) and matrix-assisted laser desorption ionisation-time of flight mass spectrometry (MALDI-TOF, Applied Biosystems 4800 Proteomics Analyzer (TOF/TOF)). TFA traces in all the peptides was exchanged for $\mathrm{HCl}$ and removed in vacuo, followed by extensive dialysis against deionized water using 500 MWCO dialysis tubing (Spectrum Europe B.V., The Netherlands).

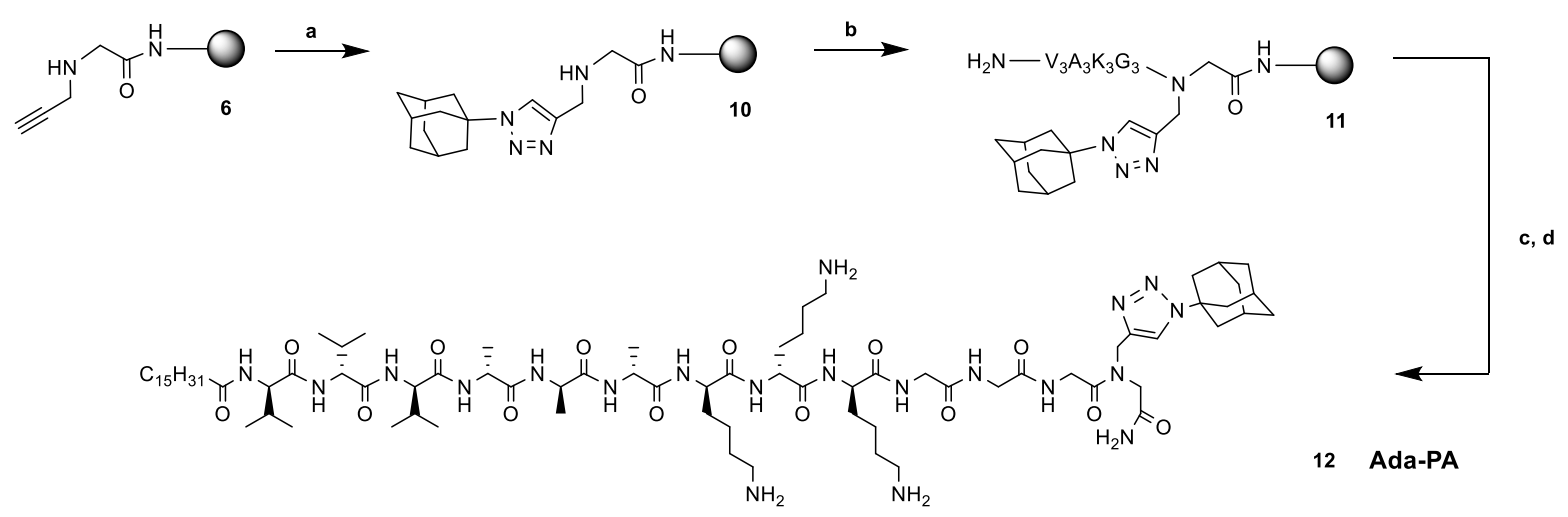

Scheme S2. Synthetic route followed for the preparation of Ada-PA. a) CuBr/ascorbic acid/1azidoadamantane in DMF/acetonitrile/DCM, DIPEA, 2,6-lutidine, r.t., 8 h. b) SPPS c) Palmitic acid/HOBT/DIC 4:4:6 in DMF/DCM 2:3, r.t., 3 h. d) TFA/TIPS/Water, r.t., 3 h. 
Table S1. Structural information of the herein reported peptide amphiphiles.

\begin{tabular}{|c|c|c|c|c|c|}
\hline Peptide & Sequence & $\begin{array}{c}\text { Expected } \\
\text { molecular } \\
\text { weight } \\
(\mathrm{g} / \mathrm{mol})\end{array}$ & $\begin{array}{c}\text { Found } \\
\mathbf{m} / \mathbf{z}\end{array}$ & $\begin{array}{c}\xi \\
(\mathbf{m V})^{* * * *}\end{array}$ & $\begin{array}{c}\text { Purity } \\
(\%) \\
* * * *\end{array}$ \\
\hline BCD-PA & $\mathrm{C}_{15} \mathrm{H}_{31} \mathrm{CONH}-\mathrm{VVVAAAKKKGGG}-(\beta$-Cyclodextrin $)-\mathrm{CONH}_{2}$ & 2575.34 & $\begin{array}{l}2598.3^{*} \\
{[\mathrm{M}+\mathrm{Na}]^{+}}\end{array}$ & $20.4 \pm 3.6$ & 93 \\
\hline Ada-PA & $\mathrm{C}_{15} \mathrm{H}_{31} \mathrm{CONH}-\mathrm{VVVAAAKKKGGG-(Adamantane)- \textrm {CONH } _ { 2 }}$ & 1594.12 & $\begin{array}{l}16115.3^{* *} \\
{[\mathrm{M}+\mathrm{Na}]^{+}}\end{array}$ & $28.2 \pm 4.5$ & 94 \\
\hline $\mathbf{K}_{3}-\mathbf{P A}$ & $\mathrm{C}_{15} \mathrm{H}_{31} \mathrm{CONH}-\mathrm{VVVAAAKKK}-\mathrm{CONH}_{2}$ & 1150.61 & $\begin{array}{l}1150.1^{* * *} \\
{[\mathrm{M}+\mathrm{H}]^{+}}\end{array}$ & $24.2 \pm 3.6$ & 96 \\
\hline
\end{tabular}

* Determined through MALDI-TOF

** Determined through ESI-MS

*** $\quad$ Determined from a 0.01 wt\% solution at $\mathrm{pH} 7$

**** Assessed through RP-HPLC 
A)

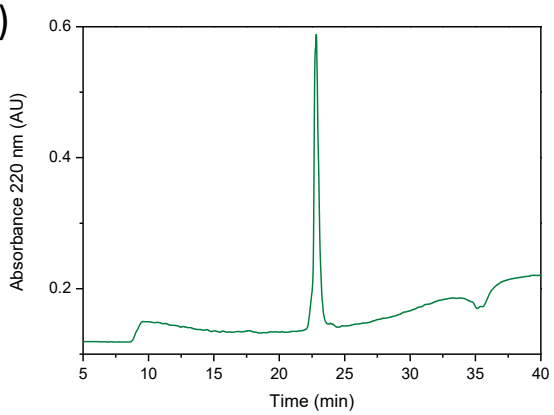

D)

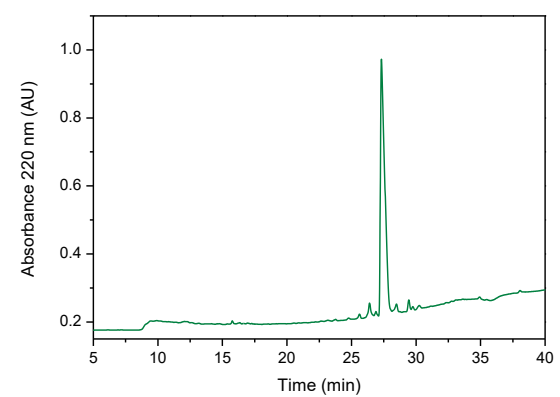

F)

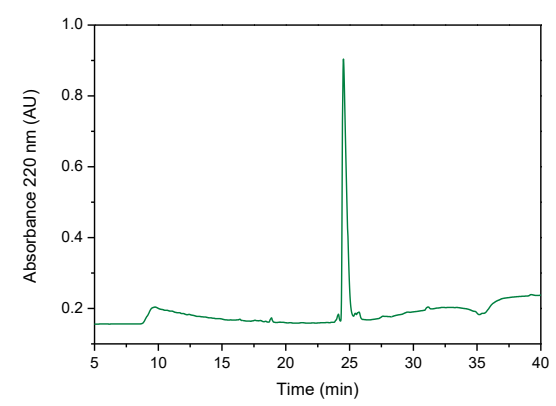

B)

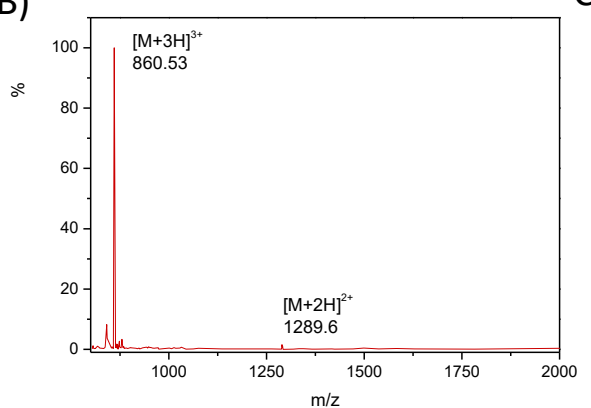

E)

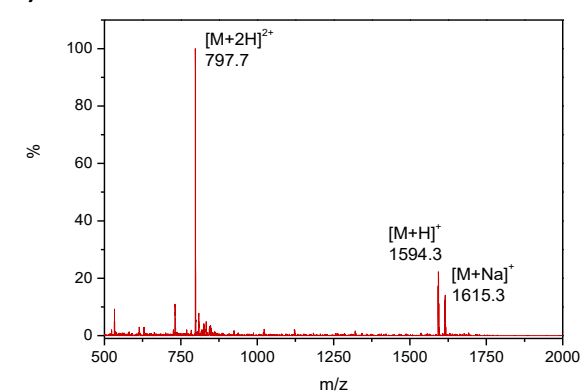

G)

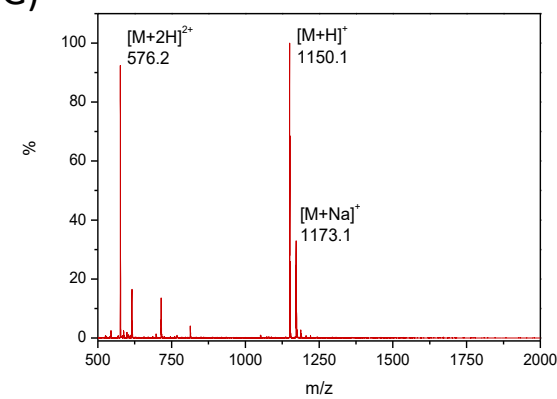

C)

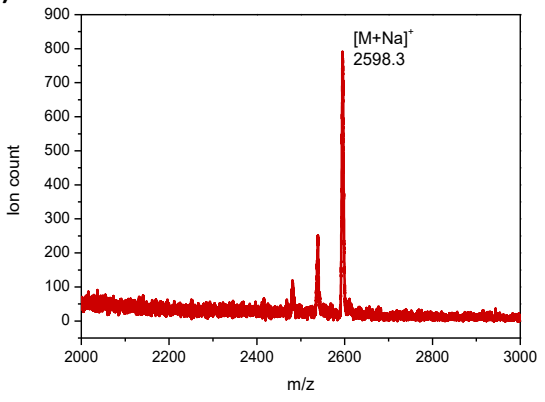

Figure S1. A) RP-HPLC, B) ESI-MS and C) MALDI-TOF traces corresponding to $\boldsymbol{\beta C D}$-PA. RP-HPLC and ESI-MS traces corresponding to D,E) Ada-PA and F,G) K3-PA respectively. 


\section{Microscopy studies}
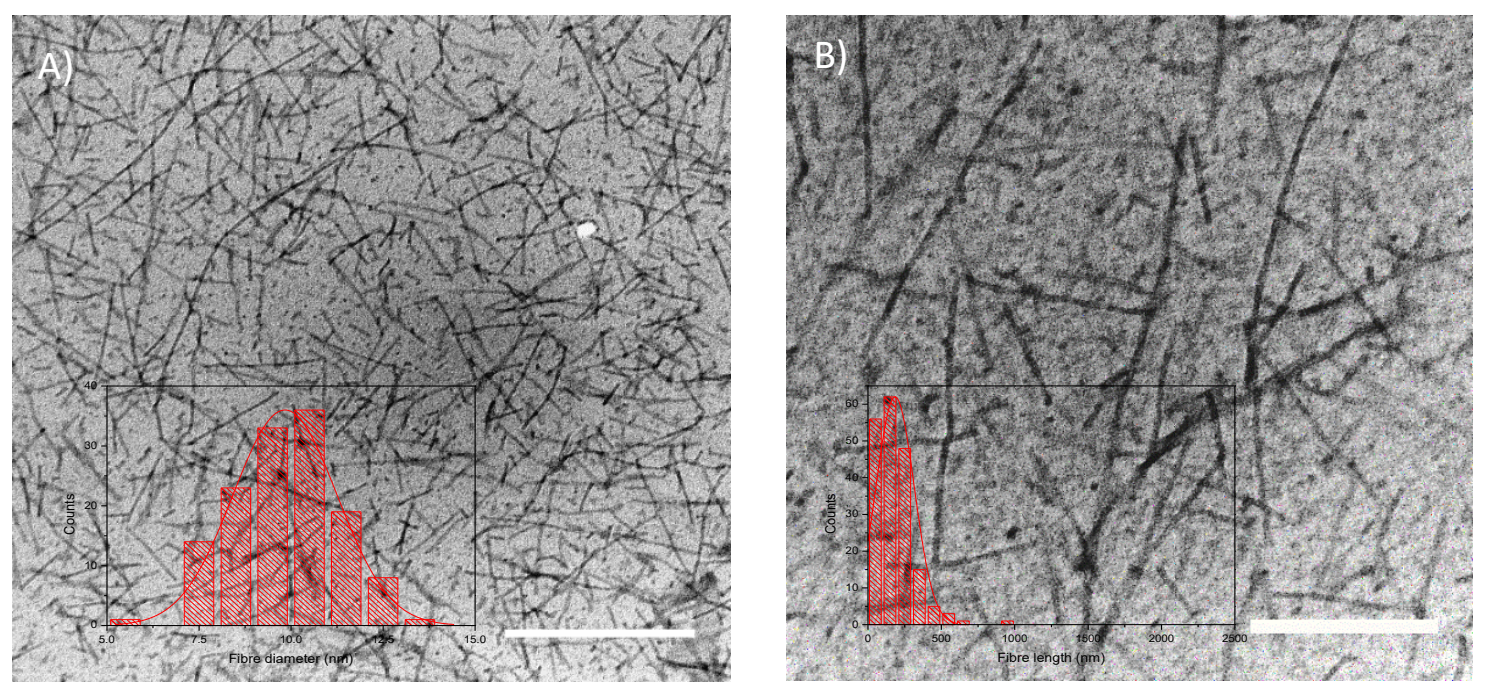

Figure S2. A,B) TEM micrographs of $\boldsymbol{\beta C D}$-PA fibers in water (scale bars $=500 \mathrm{~mm}$ and 250 $\mathrm{nm}$ in panels $\mathrm{A}$ and $\mathrm{B}$ respectively, $[\boldsymbol{\beta C D}-\mathbf{P A}]=38 \mu \mathrm{M})$ Insets: Fibre length and diameter distributions respectively.
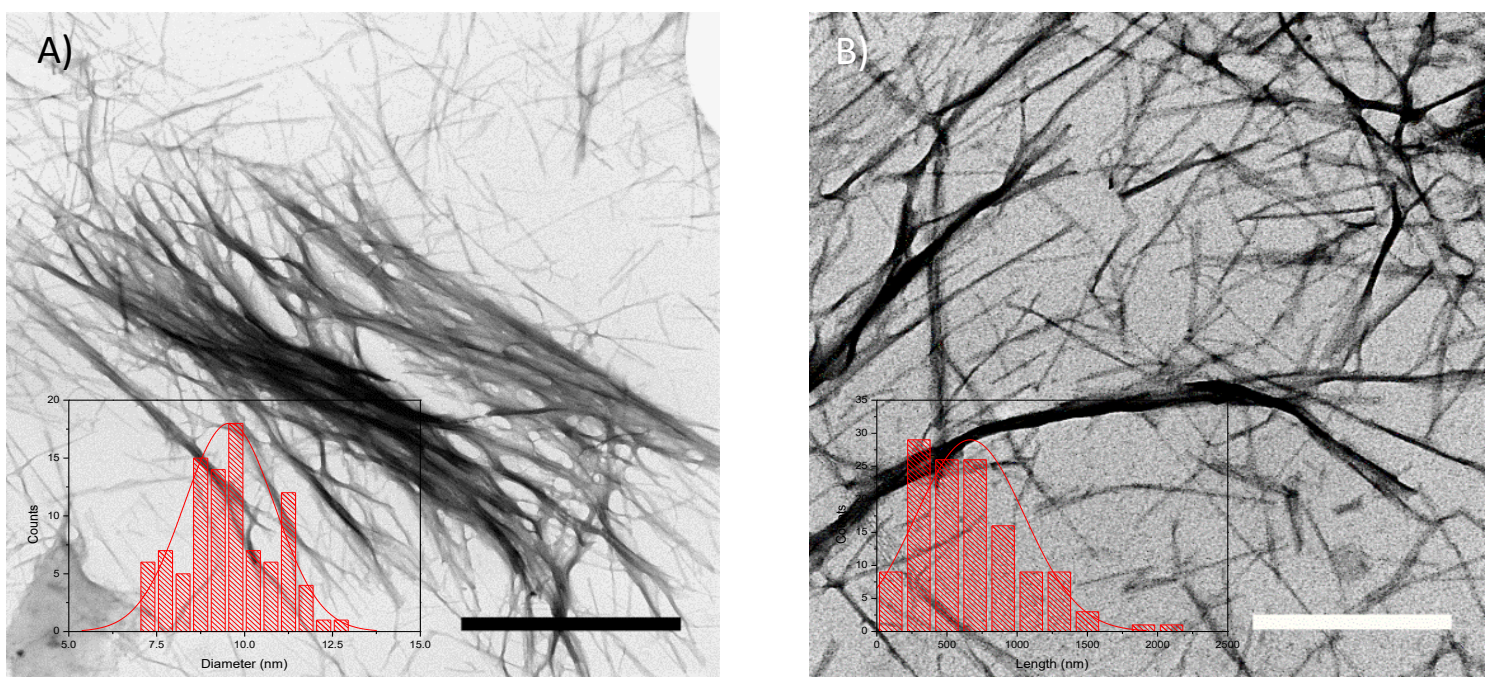

Figure S3. A,B) TEM micrographs of Ada-PA fibers in water (scale bars $=1 \mu \mathrm{m}$ and $250 \mathrm{~nm}$ in panels $\mathrm{A}$ and $\mathrm{B}$ respectively, [Ada-PA] $=63 \mu \mathrm{M}$ ) Insets: Fibre length and diameter distributions respectively. 


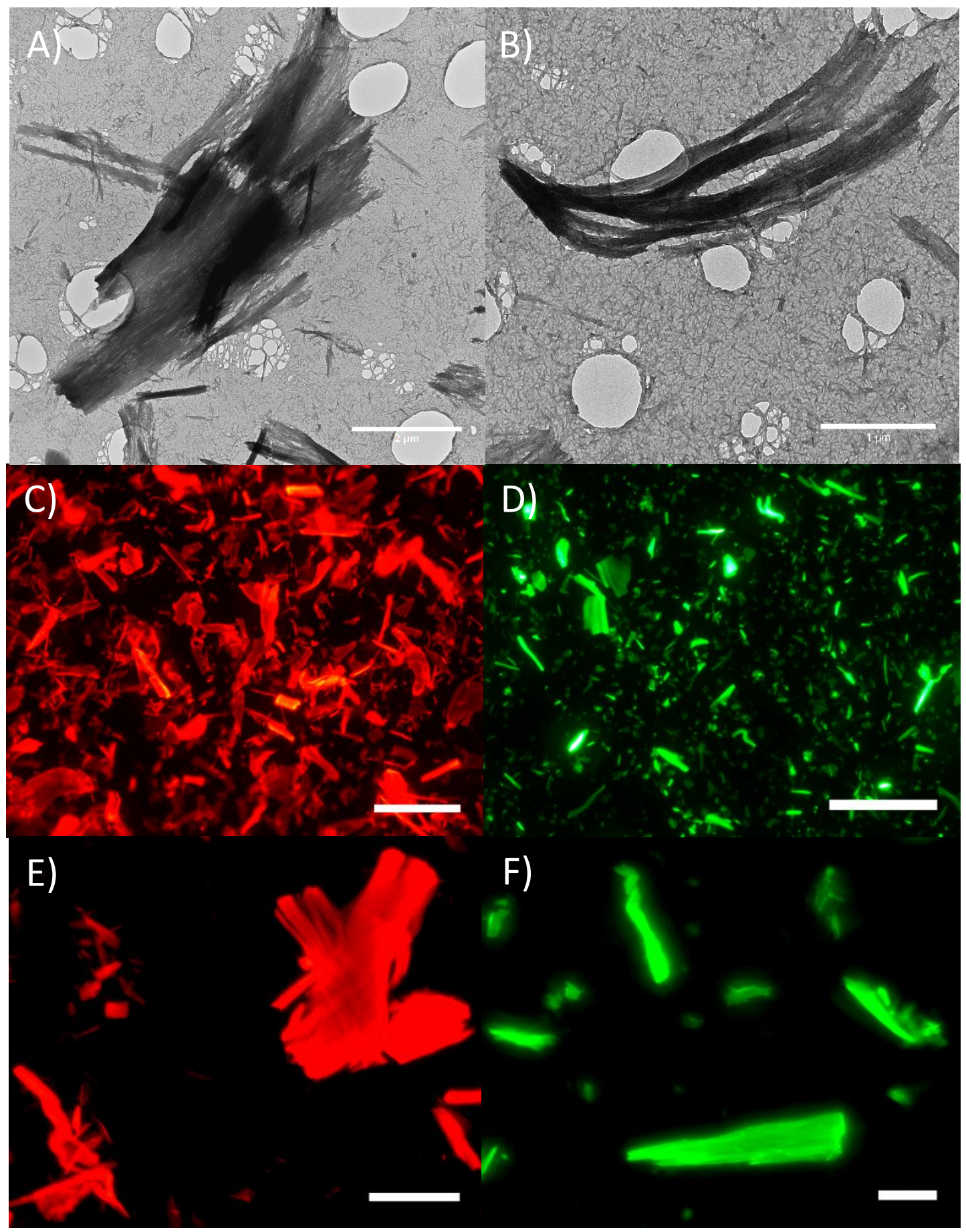

Figure S4. Micrographs showing the diversity of sizes and shapes of the peptide rafts formed by Ada-PA in HEPES buffer. A, B) TEM images of the rafts. Epifluorescence micrographs of stained rafts using C, E) Nile Red or D, F) 6-deoxy-6-[(5/6)-fluoresceinylthioureido]- $\beta$ cyclodextrin (FITC- $\beta$-CD) as fluorescent probes (scale bars $=200 \mu \mathrm{m}$ and $[$ Ada-PA] $=400$ $\mu \mathrm{M}$ for panels A-D \& scale bars $=50 \mu \mathrm{m}$ and [Ada-PA] $=150 \mu \mathrm{M}$ for panels E, F). 


\section{Spectroscopic and calorimetric determinations}

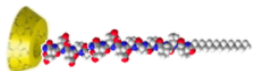

A)

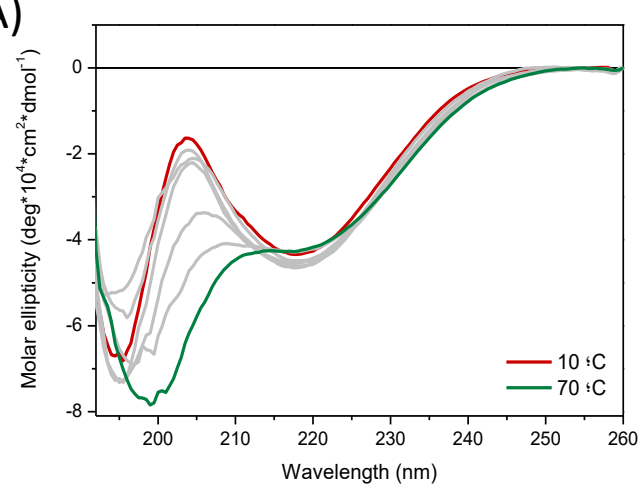

C)

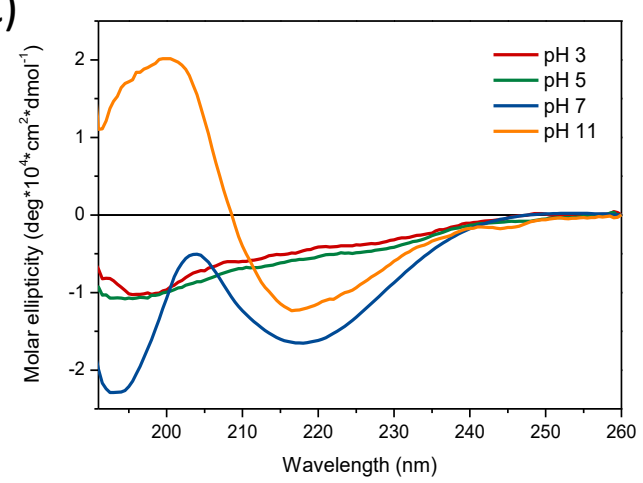

B)

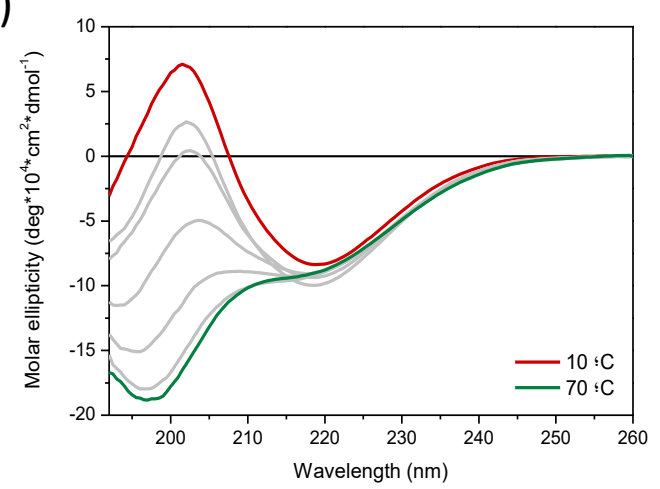

D)

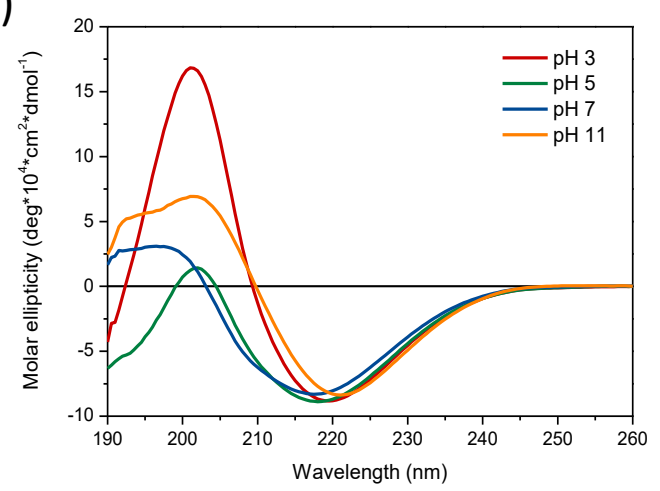

Figure S5. A) Temperature dependent CD spectra of $\boldsymbol{\beta C D - P A}$ and B) Ada-PA in water. C) $\mathrm{pH}$ dependent $\mathrm{CD}$ spectra of $\boldsymbol{\beta}$ CD-PA and D) Ada-PA in water. 


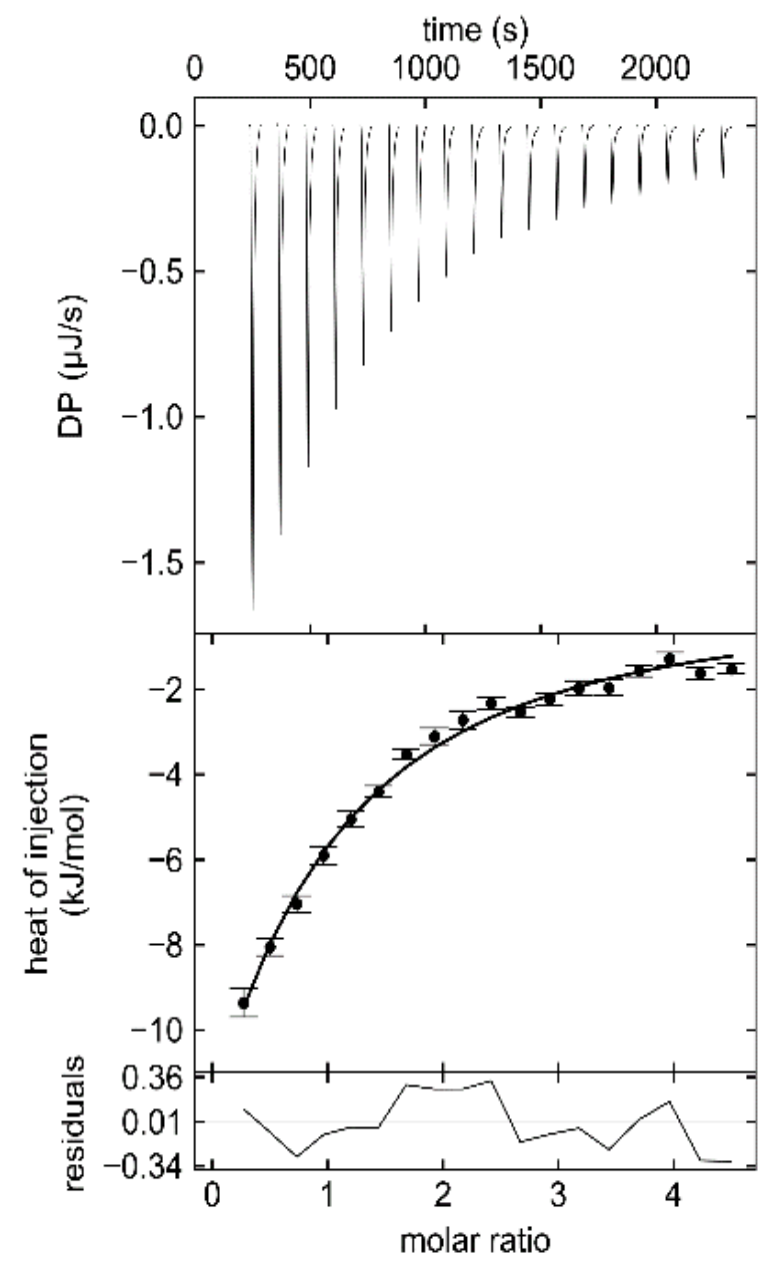

Figure S6. ITC titration of Ada-PA with $\beta C D$ evidencing the formation of a 1:1 Host-Guest inclusion complex, [Ada-PA] $=45 \mu \mathrm{M}$, $[\beta \mathrm{CD}]=1050 \mu \mathrm{M}, \quad 19 \times 20 \mu \mathrm{L}$ injections, $\mathrm{T}=25^{\circ} \mathrm{C}$, HEPES buffer $10 \mu \mathrm{M}$.

Table S2. Thermodynamic parameters associated to the host-guest interactions of $\boldsymbol{\beta C D} /$ Ada-PA and $\boldsymbol{\beta C D - P A} /$ Ada-PA systems.

\begin{tabular}{|c|c|c|c|c|c|c|}
\hline System & $\mathbf{N}$ & $\begin{array}{c}\mathbf{K}_{\mathbf{D}} \\
(\mu \mathbf{M})\end{array}$ & $\begin{array}{c}\mathbf{K a} \\
\left(\mathbf{M}^{-1}\right)\end{array}$ & $\begin{array}{c}\Delta H \\
\left(\mathrm{~kJ}^{\circ} \mathrm{mol}^{-1}\right)\end{array}$ & $\begin{array}{c}\Delta G \\
\left(k J \cdot \mathrm{mol}^{-1}\right)\end{array}$ & $\begin{array}{c}-\mathrm{T} \Delta \mathrm{S} \\
\left(\mathrm{kJ} \bullet \mathrm{mol}^{-1}\right)\end{array}$ \\
\hline BCD / Ada-PA & $0.95 \pm 0.07$ & $25.6 \pm 6.4$ & $(3.91 \pm 0.98) \times 10^{4}$ & $-14.56 \pm 2.3$ & -26.23 & -11.67 \\
\hline
\end{tabular}


A)

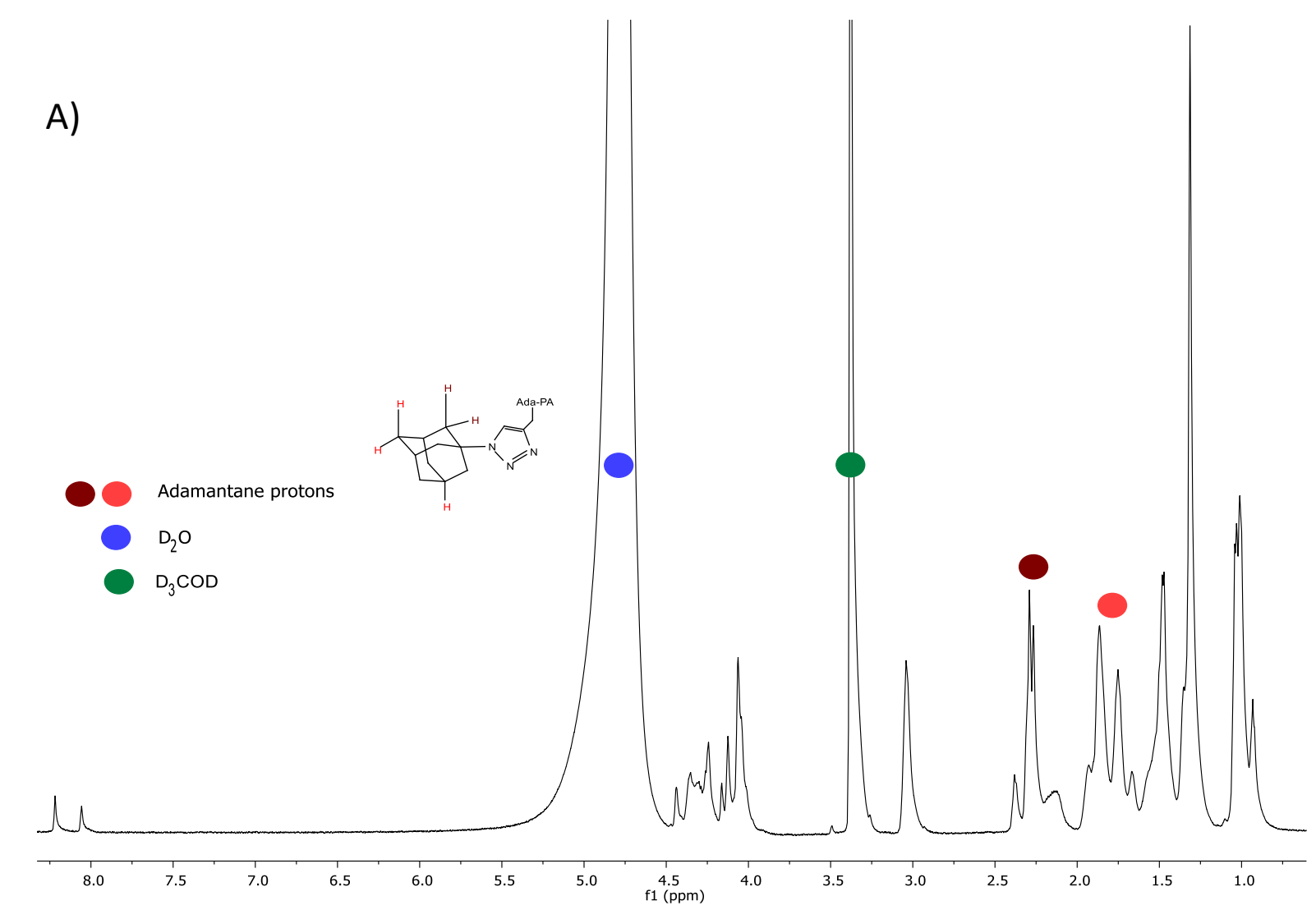

B)

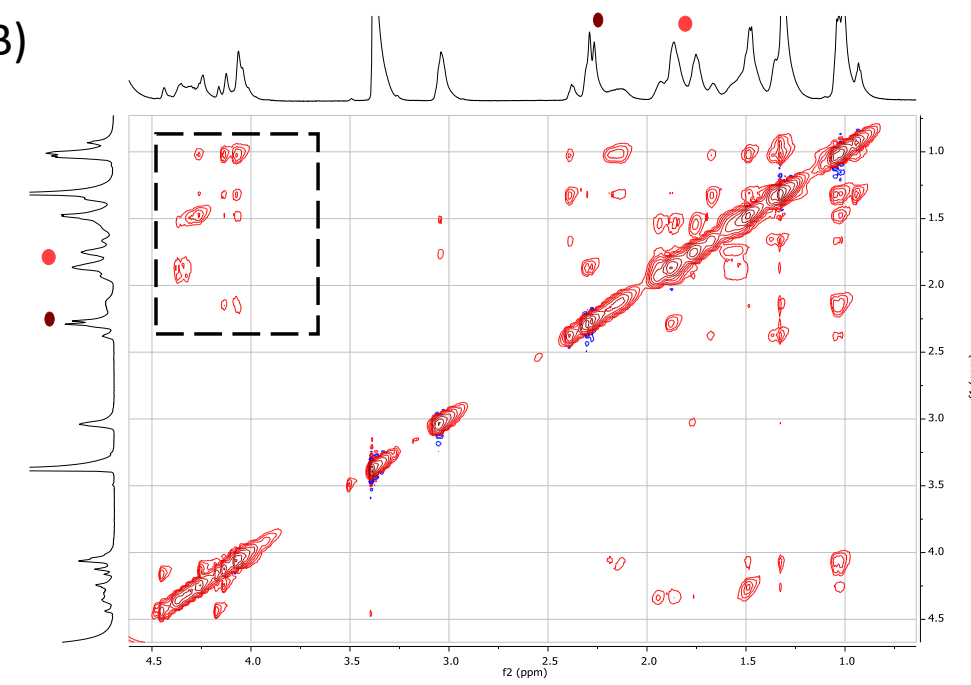

C)

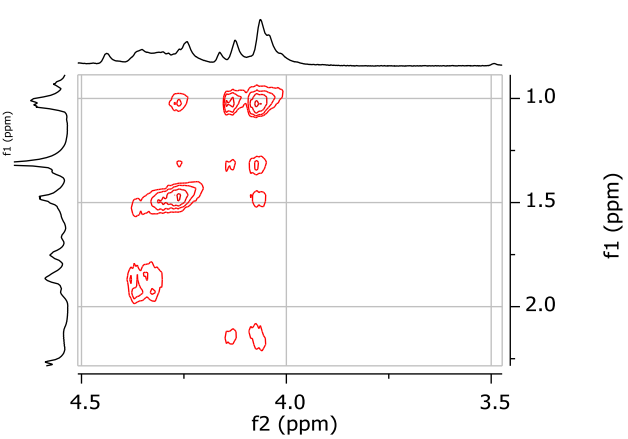

Figure S7. NMR spectra corresponding to Ada-PA and its complex with free $\beta$-cyclodextrin $(\beta C D)$. A) ${ }^{1} \mathrm{H}-\mathrm{NMR}$ and B) NOESY spectra corresponding to Ada-PA $(600 \mathrm{MHz}, 7.5 \mathrm{mM}$, $\mathrm{D}_{2} \mathrm{O} / \mathrm{D}_{3} \mathrm{COD} 2: 1,298 \mathrm{~K}$ ). C) Zoom of the indicated region from panel B) (it continues on the next page). 
D)

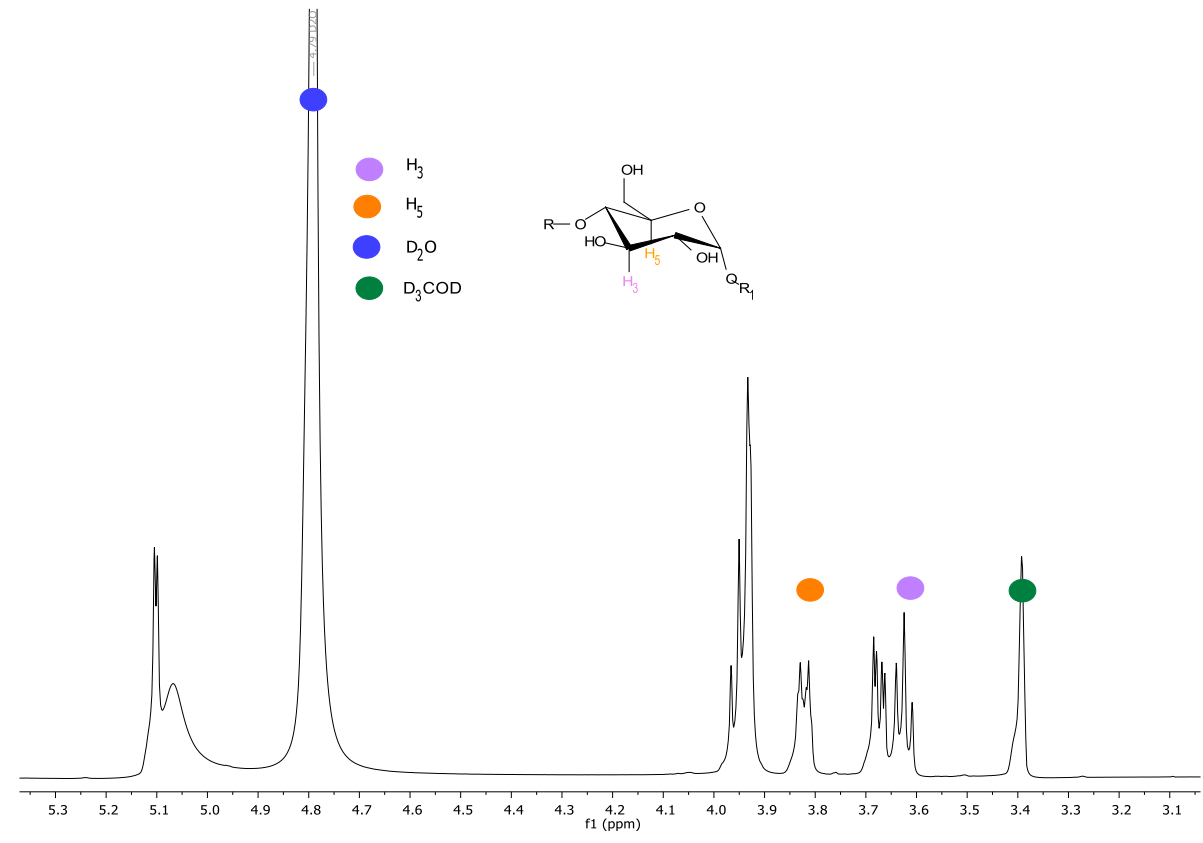

E)

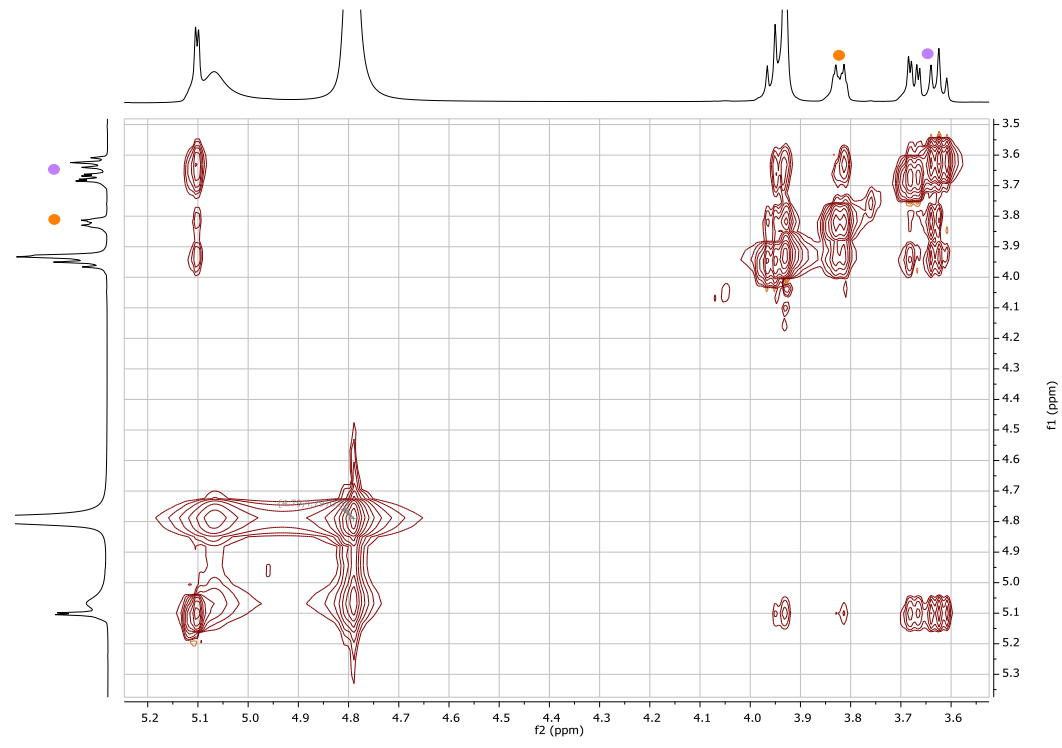

Figure S7 (continued). D) ${ }^{1} \mathrm{H}$-NMR spectrum corresponding to $\beta$-cyclodextrin $(\beta \mathrm{CD})(600$ $\mathrm{MHz}, 7.5 \mathrm{mM}, \mathrm{D}_{2} \mathrm{O} / \mathrm{D}_{3} \mathrm{COD} 2: 1,298 \mathrm{~K}$ ). E) NOESY spectrum of the same sample (it continues on the next page). 

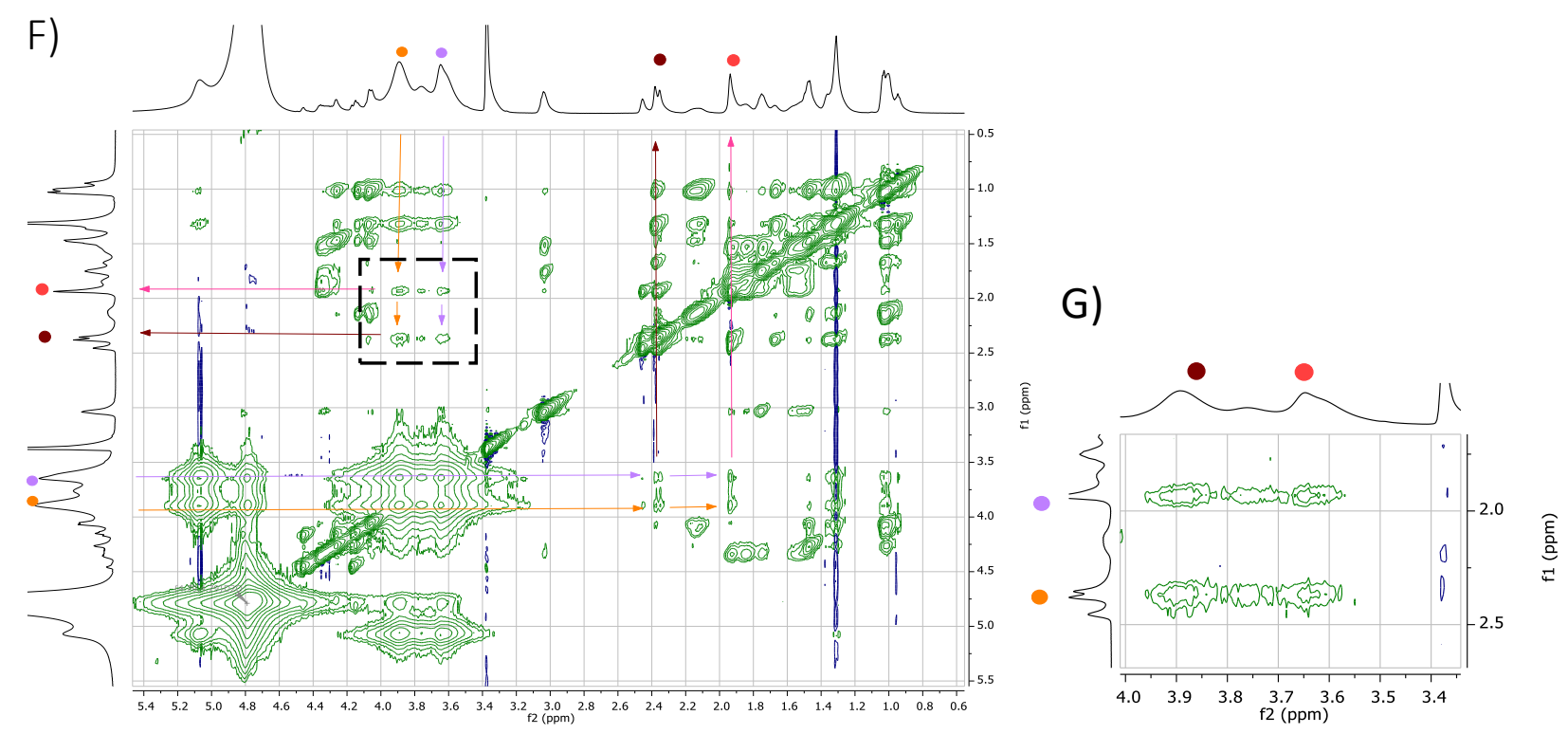

H)

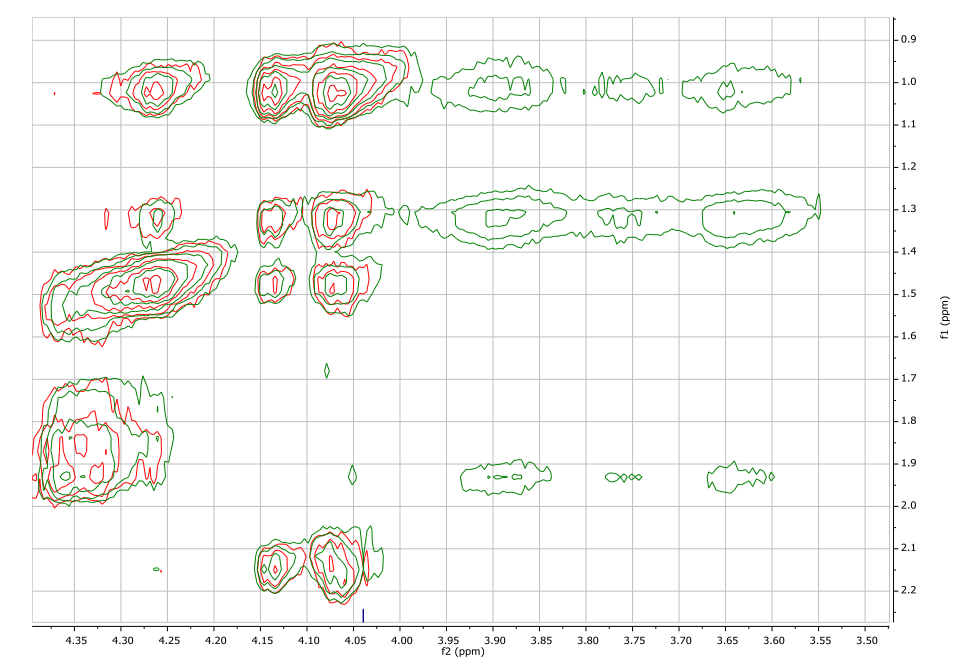

Figure S7 (continued). F) NOESY spectra corresponding to Ada-PA mixed with $\beta$ CD (600 $\mathrm{MHz}, 7.5 \mathrm{mM}$ each, $\left.\mathrm{D}_{2} \mathrm{O} / \mathrm{D}_{3} \mathrm{COD} 2: 1,298 \mathrm{~K}\right)$. G) Zoom of the indicated region from panel F). $\mathrm{H})$ Superposition of panels $\mathrm{C}$ (in red) and $\mathrm{G}$ (in green) showing that the cross-peaks in green arise from the interaction between adamantane protons of Ada-PA and $\mathrm{H}_{3}$ (violet) and $\mathrm{H}_{5}$ (orange) protons from $\beta \mathrm{CD}$. 


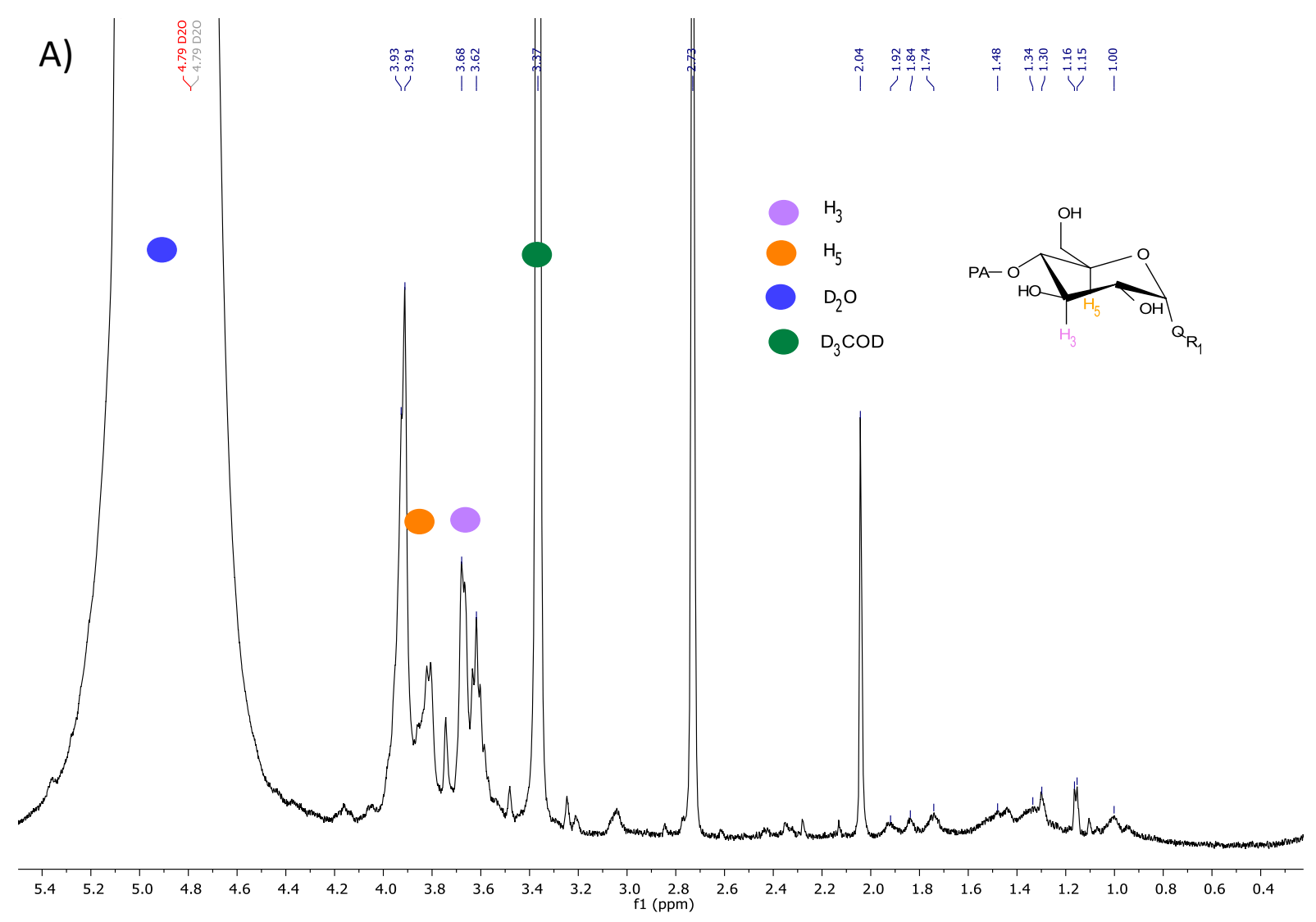

Figure S8. A) ${ }^{1} \mathrm{H}-\mathrm{NMR}$ spectra corresponding to $\boldsymbol{\beta}$ CD-PA $\left(600 \mathrm{MHz}, 7.5 \mathrm{mM}, \mathrm{D}_{2} \mathrm{O}_{2} \mathrm{D}_{3} \mathrm{COD}\right.$ 2:1,298 K) (it continues on the next page). 

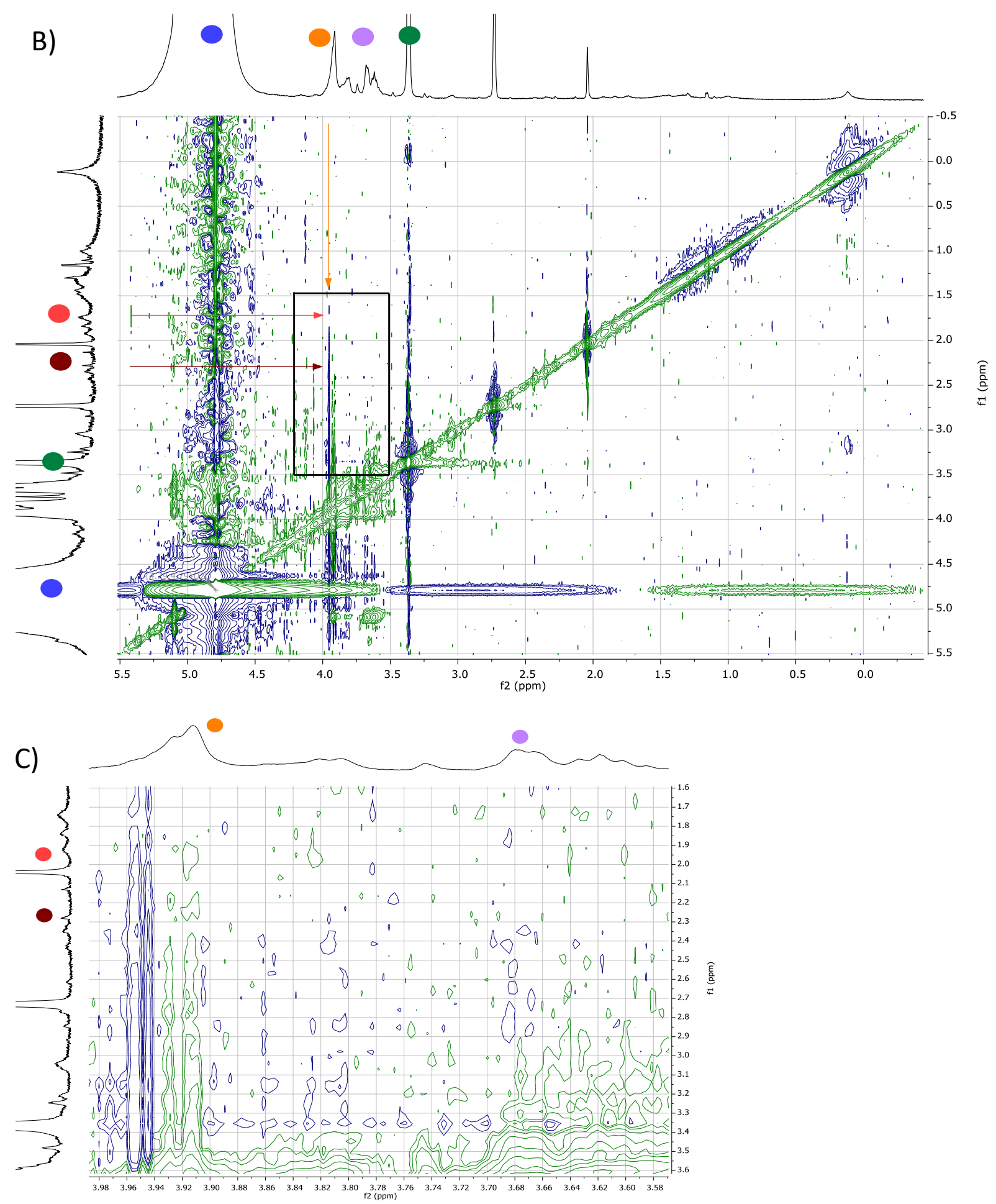

Figure S8 (continued). B) NOESY spectra corresponding to Ada-PA mixed with $\boldsymbol{\beta C D}$-PA $\left(600 \mathrm{MHz}, 7.5 \mathrm{mM}\right.$ each, $\left.\mathrm{D}_{2} \mathrm{O} / \mathrm{D}_{3} \mathrm{COD} 3: 1,298 \mathrm{~K}\right)$. C) Zoom of the indicated region from panel B). 


\section{Rheological and stability studies}

Table S3. Storage (G') and loss (G', ) moduli of gels with increasing concentration of BCD-PA/Ada-PA host-guest pair.*

\begin{tabular}{ccc}
\hline $\begin{array}{c}\text { K3-PA/קCD-PA/Ada-PA ratio } \\
(\mathbf{m o l} \%)\end{array}$ & $\mathbf{G}^{\prime}(\mathbf{P a})$ & $\mathbf{G}^{\prime \prime}(\mathbf{P a})$ \\
\hline $100: 0: 0$ & $2806 \pm 466$ & $401 \pm 80$ \\
\hline $90: 5: 5$ & $4470 \pm 1206$ & $905 \pm 270$ \\
\hline $80: 10: 10$ & $5152 \pm 880$ & $1161 \pm 247$ \\
\hline $70: 15: 15$ & $3100 \pm 575$ & $756 \pm 120$ \\
\hline
\end{tabular}

$* \pm$ S.D. $\mathrm{n}>3$ 


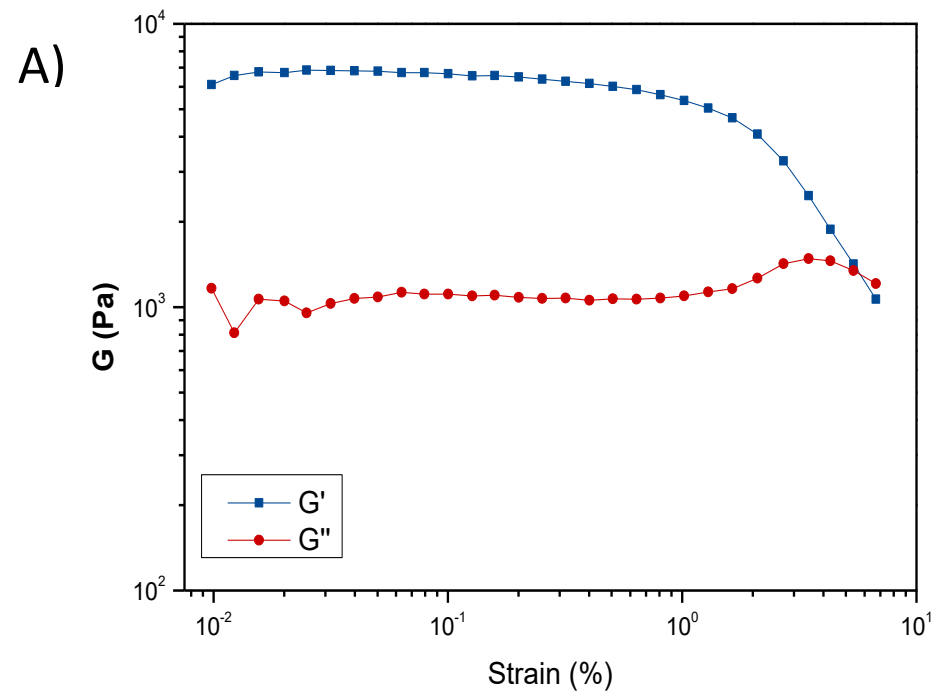

B)

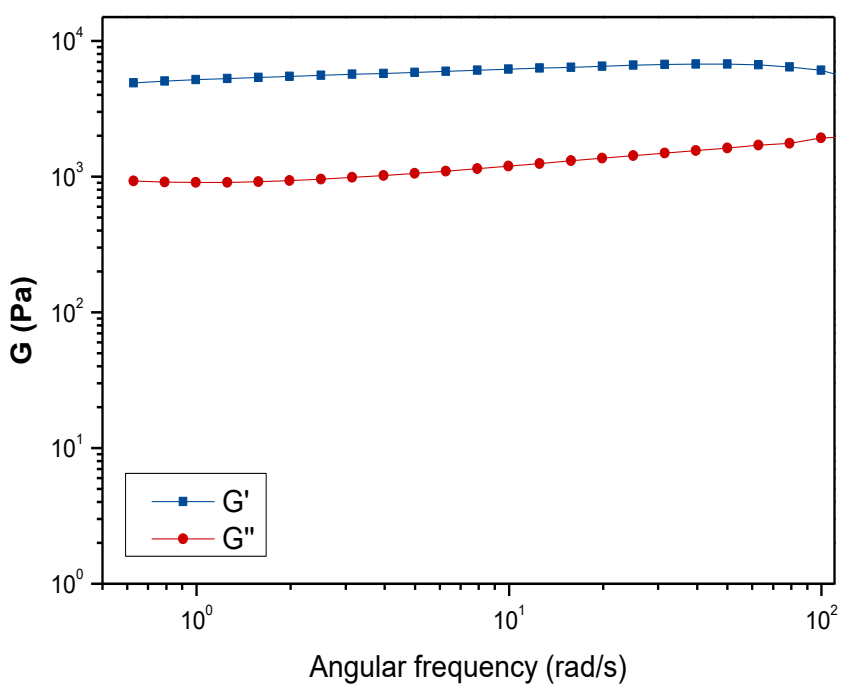

Figure S9. A) Oscillatory strain and B) oscillatory frequency sweeps of a representative ternary K3-PA/BCD-PA/Ada-PA 70:15:15 mol\% gel (1 wt \%). 

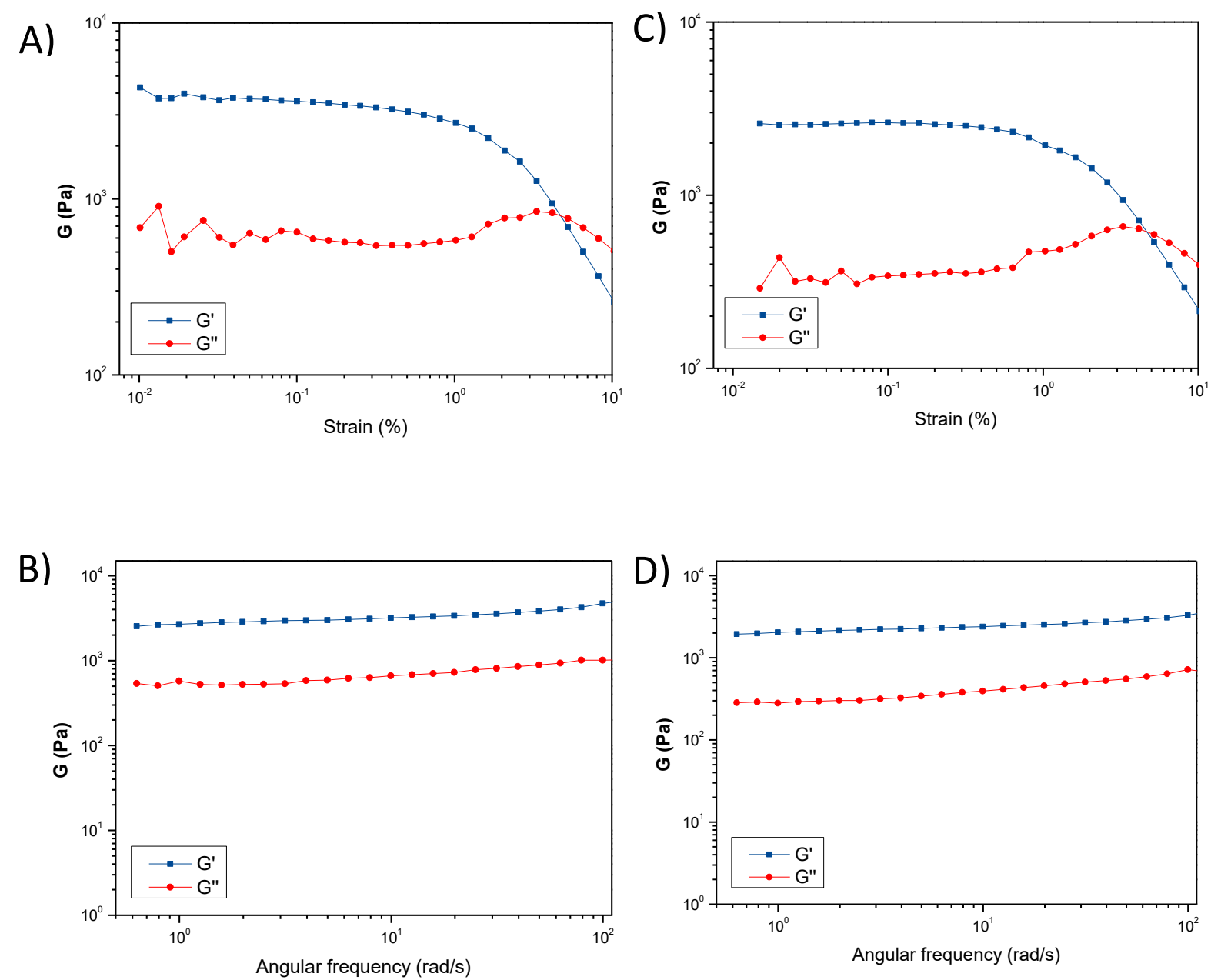

Figure S10. A) Oscillatory strain and B) oscillatory frequency sweeps of a binary $\mathbf{K}_{3}-\mathbf{P A} / \boldsymbol{\beta C D}$-PA 70:30 hydrogel (1 wt \%). C) Oscillatory strain and D) oscillatory frequency sweeps of a binary K3-PA/Ada-PA 70:30 hydrogel (1 wt \%). 


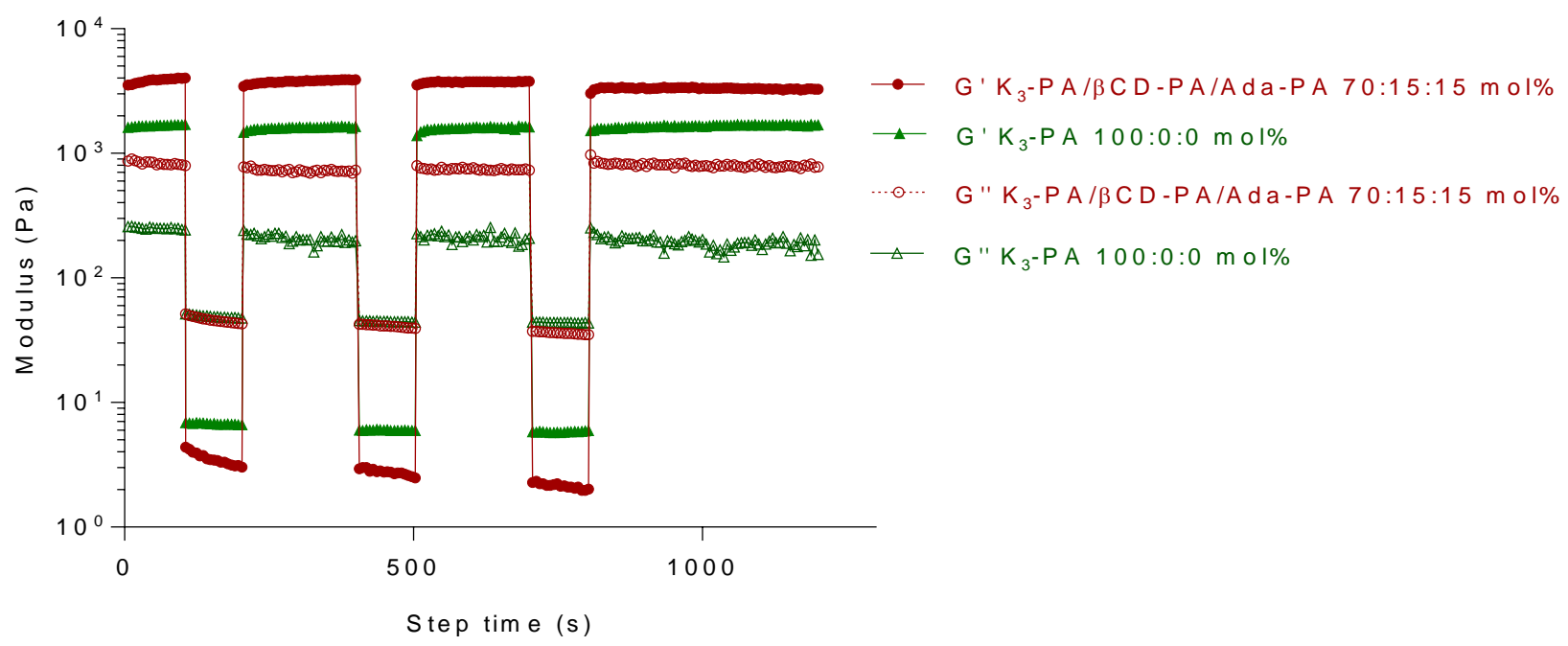

Figure S11. Continuous step strain measurements (creep and recovery) of control K3-PA hydrogel (1 wt $\%$, green traces) and $\mathbf{K}_{3}-\mathbf{P A} / \boldsymbol{\beta C D}$-PA/Ada-PA 70:15:15 mol\% hydrogel (1 $\mathrm{wt} \%$, red traces). 


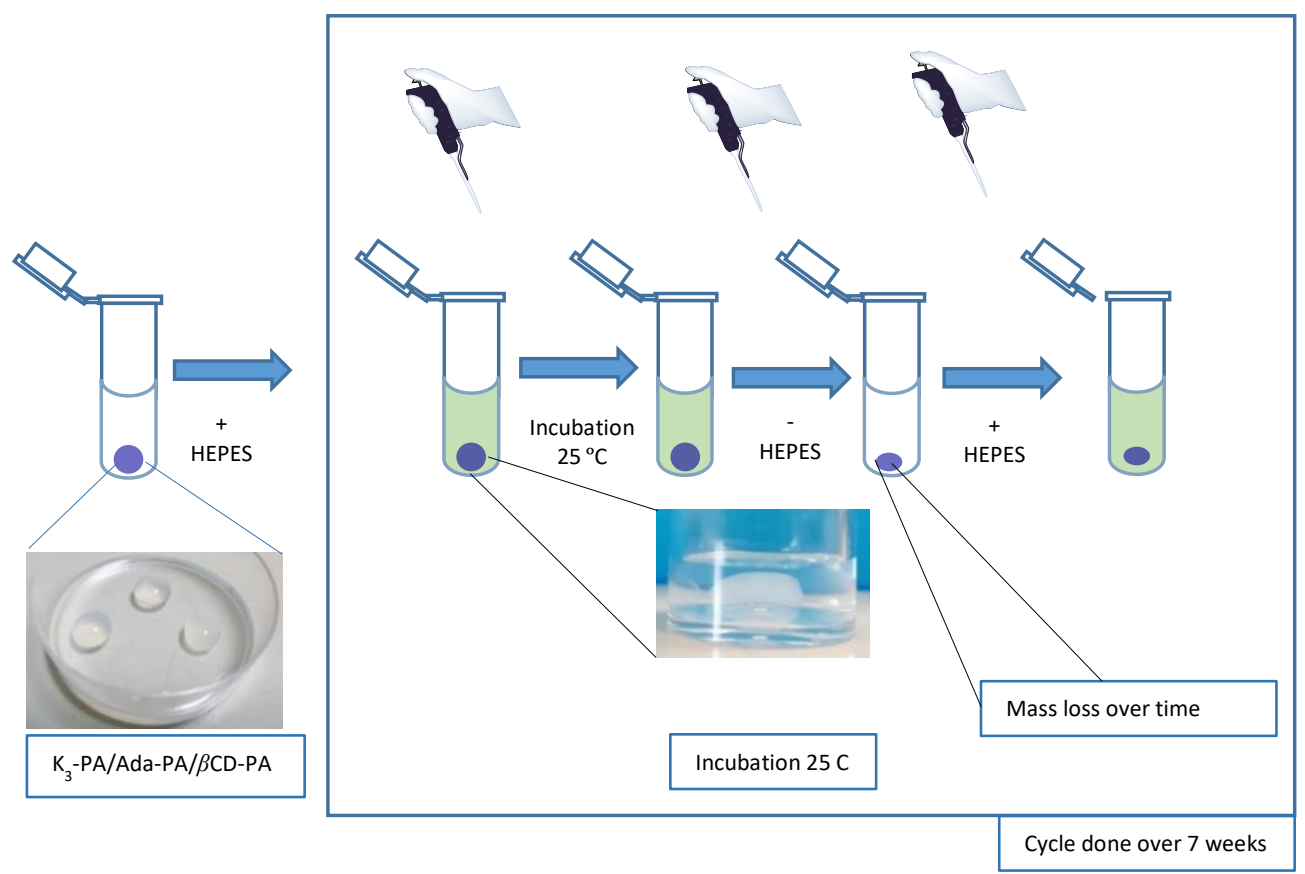

Figure S12. Schematic showing the experimental set-up for degradation assessment of K3-PA/ $\boldsymbol{\beta C D}$ CDA/Ada-PA gels over time $(\mathrm{n}>5)$. 


\section{Cell viability studies}

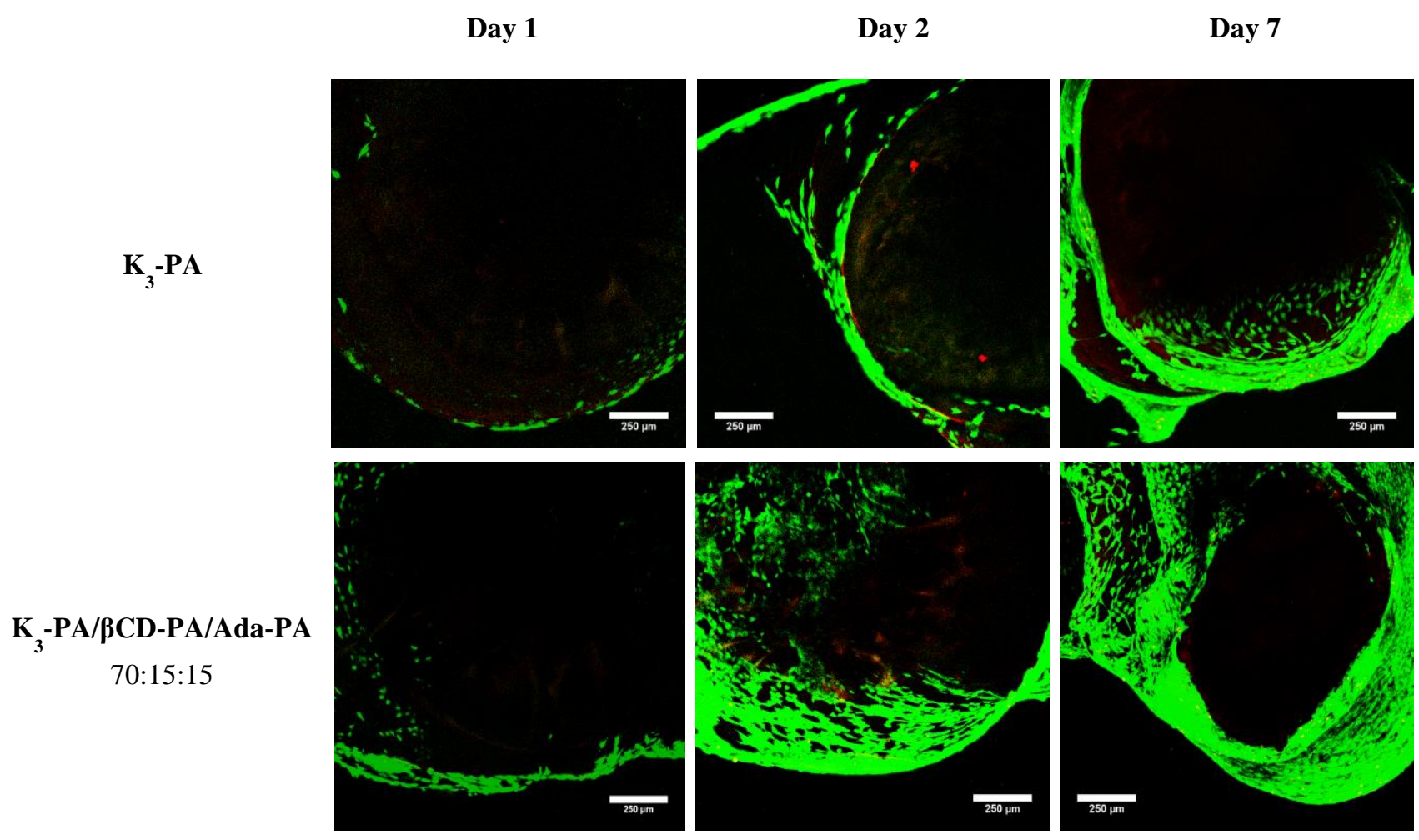

Figure S13. NIH-3T3 fibroblasts LIVE-DEAD assay (green: calcein AM, alive cells; red: ethidium homodimer-1 (EthD-1), dead cells) after culture onto K3-PA/Ada-PA• $\boldsymbol{\beta C D - P A}$ 70:15:15 mol\% and K3-PA 1 wt \% as control hydrogels. 


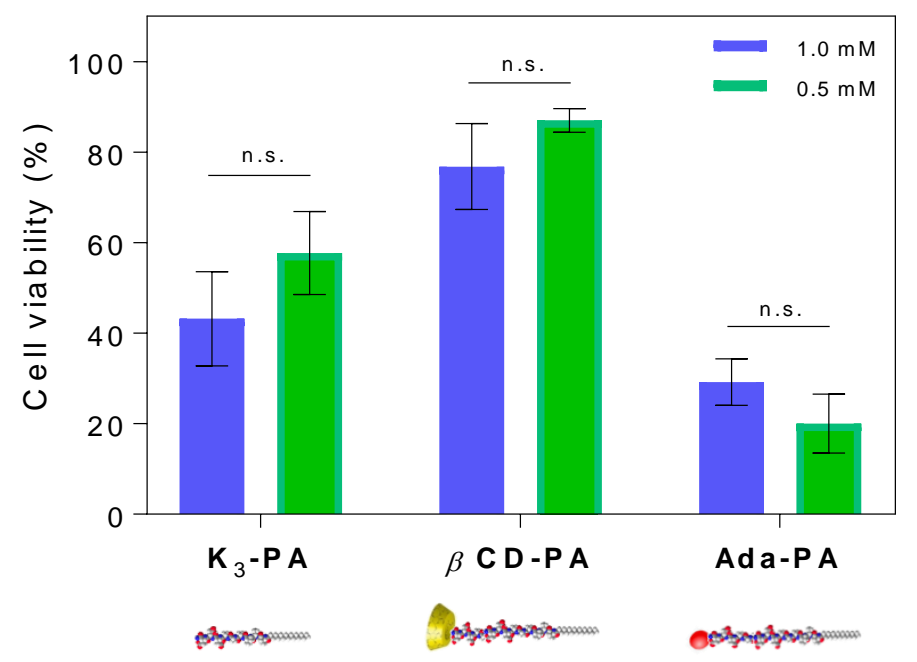

Figure S14. NIH-3T3 fibroblasts LIVE-DEAD assay after culture in $1.0 \mathrm{mM}$ and $0.5 \mathrm{mM}$ $K_{3}-P A$, Ada-PA and $\beta C D-P A$ solutions. 


\section{References}

(1) Zuckermann, R. N.; Kerr, J. M.; Kent, S. B.; Moos, W. H. Efficient Method for the Preparation of Peptoids [Oligo (N-Substituted Glycines)] by Submonomer SolidPhase Synthesis. J. Am. Chem. Soc. 1992, 114 (26), 10646-10647.

(2) Tang, W.; Ng, S.-C. Facile Synthesis of Mono-6-Amino-6-Deoxy- $\alpha-, \beta-, \gamma-$ Cyclodextrin Hydrochlorides for Molecular Recognition, Chiral Separation and Drug Delivery. Nat. Protoc. 2008, 3 (4), 691-697.

(3) Tan, T.; Tan, T.; Ng, S.; Wang, Y.; Xiao, Y. Synthesis of Mono-6-Tosyl- $\beta$ Cyclodextrin, a Key Intermediate for the Functional Cyclodextrin Derivatives. Protoc. Exch. 2011.

(4) Metaferia, B. B.; Rittler, M.; Gheeya, J. S.; Lee, A.; Hempel, H.; Plaza, A.; StetlerStevenson, W. G.; Bewley, C. A.; Khan, J. Synthesis of Novel Cyclic NGR/RGD Peptide Analogs via on Resin Click Chemistry. Bioorg. Med. Chem. Lett. 2010, 20 (24), 7337-7340.

(5) Keller, S.; Vargas, C.; Zhao, H.; Piszczek, G.; Brautigam, C. A.; Schuck, P. HighPrecision Isothermal Titration Calorimetry with Automated Peak-Shape Analysis. Anal. Chem. 2012, 84 (11), 5066-5073.

(6) Brautigam, C. A.; Zhao, H.; Vargas, C.; Keller, S.; Schuck, P. Integration and Global Analysis of Isothermal Titration Calorimetry Data for Studying Macromolecular Interactions. Nat. Protoc. 2016, 11 (5), 882-894.

(7) Li, G.; Wu, J.; Wang, B.; Yan, S.; Zhang, K.; Ding, J.; Yin, J. Self-Healing Supramolecular Self-Assembled Hydrogels Based on Poly( L -Glutamic Acid). Biomacromolecules 2015, 16 (11), 3508-3518. 